\title{
2020 Miles Conrad award lecture: James G. Neal
}

\author{
James G. Neal* \\ University Librarian Emeritus, Columbia University, New York, NY, USA
}

\begin{abstract}
This paper is based upon the 2020 Miles Conrad Award Lecture that was given by James G. Neal at the inaugural NISO Plus conference held from February 23-25, 2020 in Baltimore, MD (USA). The lecture provided a brief look back at some of the key information industry challenges of the past four decades, but more importantly it highlighted the challenges facing the community today such as the democratization of creativity; the born-digital explosion; policy chaos including privacy, market monopoly, global intellectual property, and intellectual freedom; the challenges of diversity, equity, and inclusion; and human-machine symbiosis and blended reality. The lecture lists five commandments to which all stakeholders in the Information Community need to adhere in order to be successful moving forward together: (1) Thou shall preserve the cultural and scientific record; (2) Thou shall fight the information policy wars; (3) Thou shall be supportive of the needs of your users and your readers; (4)Thou shall cooperate in new and more rigorous ways; and (5) Thou shall work together to improve knowledge creation, evaluation, distribution, use, and preservation.
\end{abstract}

Keywords: Miles Conrad lecture 2020, library transformation, information community challenges, information disruptors

I was deeply appreciative and honored to have been selected for the 2020 Miles Conrad Award [1] from NFAIS and NISO. What a way to start a new decade! But I was distraught when I realized that the awards ceremony would be held during the inaugural NISO Plus conference from February 23-25, 2020, and that this conflicted with a longstanding commitment to be in Brazil at that time. Thankfully, I was allowed to give the Miles Conrad Lecture at the conference in an asynchronous way and to share some reflection on our work. It is that presentation upon which this paper is based.

I had been given three questions to answer and a total of approximately fifteen minutes to respond. The first question was the following: "When you started in library leadership what were the pressing issues facing the information community and how have these issues changed over your career?" The answer from forty-six years ago - is that funding was the main issue - always funding. There was never enough. And another issue was imminent technology. Today the pressing issues are new collaborative strategies and social unrest.

The second question put to me was "What has been the most disruptive change in information dissemination over your career, and how well or poorly have we as a community reacted to that change?" The answer - global scholarly communication, online learning, user-managed applications, Big Data, streaming access, smart objects and systems - and unfortunately, I do not believe that we have always reacted very well.

\footnotetext{
*Tel.: +1 (212) 854 2523; E-mail: jneal@columbia.edu.
} 
The final question that I was given is "What do you see as the biggest challenges faced by the community of librarians, publishers, and information intermediaries over the next five to ten years?" For me, there are many challenges including the democratization of creativity; the born-digital explosion; policy chaos including privacy, market monopoly, global intellectual property, and intellectual freedom; the challenges of diversity, equity, and inclusion; and human-machine symbiosis and blended reality.

I have noticed that over the last several years my presentations at professional conferences have become more alarmist and strident. I have come to subscribe to the Emerson adage that sometimes a scream is better than a thesis [1]. Prognosis exercises offer opportunities to set aside reason, to avoid evidence, and just speculate with abandon. The futures of libraries, publishers, and information intermediaries are particularly challenging to define as the community of interest is narrow and the implications of error are modest.

Ken Kasey, author of One Flew over the Cuckoo's Nest, once commented in an interview, "You can count the seeds in the apple, but you cannot count the apples in the seed". We have entered a period of gross mutability, a state of constant change, of productive and powerful chaos, of hybrid strategies and maverick structures, of radical shifts in our traditional staffing, of massive leadership turnover, and of essential creativity and advancing individual and collective visions.

There are in my view, three essential elements for success during this period. First, we must have hope - believe in and aspire to expanding relevance and impact. Second, we must achieve power - to have authority, influence, and respect. And third, we must focus less solely upon ideas, and more on action. We need to get things done. We must advance primal innovation, a basic commitment to risk and experimentation, and radical collaboration, moving well beyond the "kumbaya" to more deep and systemic partnerships.

The library has always been a fundamental partner in the learning and research process. But key changes in the information, technology, economic, social, and political environments are challenging this relationship and raising critical questions about the value of libraries in the community. Do 20th-century professional skills still matter? Do students see the library as central to their learning? Do researchers still need libraries? Do the new roles that libraries are advancing - as aggressive consumers; as intermediaries and aggregators; as publishers and educators; as creative space makers; as entrepreneurs and policy advocates - present a refreshed opportunity for innovation and library centrality? As we look out over the next decade, libraries will be increasingly defined by active descriptors such as convener, enabler, distributor, advocate, and archive. They will be less defined by static terms such as infrastructure, platform, repository, and portal to resources and applications. Libraries recognize that content is not enough - quality equals content plus functionality.

The future is not only about what content libraries have, but it is also about what they can do with that content. I believe that this will be directed more and more towards the consumer. Open resources for learning, research, and recreation, and open-source tools supporting innovation, collaboration, and productivity will be more prevalent in the global economy. Self-publishing and niche technology development will dominate. Information policy wars will dictate national and global, legal, and legislative, debates. Libraries will apply new knowledge to new resources to produce new goods and new services. That is, the library community will help to develop the market. We will focus more aggressively on managing the costs and increasing the benefit; i.e., we will add value. We will deliberately think about challenges and unmet needs; i.e., we will seek solutions. Measured transformation will be the key. In line with the definition of the term "transformation," libraries will change in composition or structure, in what they are and what they do. The will change in outward form or appearance, in how they are viewed, and how they are understood. And they will change in character and condition and in how they do things. 
I recall the wonderful Mel Brooks film, History of the World Part I. There is a great scene when Brooks, as Moses, is coming down the mountain, carrying three large tablets and announces. "Children of Israel, I have 15". He suddenly trips and one of the tablets crashes to the ground. He picks himself up and continues to proceed down the mountain while restating "Children of Israel, I have 10 commandments". I think we all applaud the loss of those five additional suggestions, but allow me to speculate what they were.

\section{Commandment \#1: "Thou shall preserve the cultural and scientific record."}

We are in trouble with this one. Today, the world is producing vast amounts of digitized and borndigital content. The volume, complexity, and dynamism of this information challenge force us to think creatively about how we capture, organize, and preserve information for the long term, and provide for digital content usability. We need the technologies, the infrastructure, the financial resources, and the shared responsibility and strength of will to accomplish such an objective. We have done a modest job, at best, in the analog record, but we are failing in our management of the digitized record, including published e-journals, e-books, e-media, and e-documents. As for the explosion of born-digital materials, there has been some minimal activity, but no sustained programs and investments have emerged. This is an issue of integrity in the scholarly record. We must maintain human records as complete, unimpaired, and undivided as possible, and avoid the current state of repository chaos.

At the core of digital preservation and archiving are four basic principles: first, libraries must hold the content, that is, archive it as a repository; second, they must enable access - the repository as persistence; third, they must secure the content - archive as curation; and fourth they must care for the content - the repository as steward.

\section{Commandment \#2: "Thou shall fight the information policy wars."}

The library community must more rigorously represent and advance the public interest and the needs of users and readers in critical information policy areas in national and global forums. We must embrace an expanded role in the legislative, legal, and political arenas. The policy areas of interest are numerous and complex. They include intellectual freedom and concerns over censorship, privacy, and civil liberties; access to government information; network neutrality and telecommunications policy; open access to research and educational content; and finally, copyright and intellectual property.

Copyright is an area of particular concern. There are broad copyright exceptions for libraries which allow for such things as copies for users, inter-library loan, access for the print-disabled, preservation, and of course, Fair Use. And while these notable exceptions have been strengthened by recent court decisions, they are under threat. The threat comes from an increasing focus on international agreements and treaties that influence national laws and the fact that more and more of the publications and databases being provided by libraries are covered under contract law - not the public law of copyright. In addition, technological controls and digital rights management systems are reducing the ability to apply fair use and other valuable exceptions.

\section{Commandment \#3: "Thou shall be supportive of the needs of your users and your readers."}

Libraries are developing a more sustained and actionable understanding of our user communities. Our users are probably far more diverse than we realize. We intersect with our users well beyond the walls of our physical spaces and the current tools for measuring, surveying, observing, and listening to our users are inadequate. Users want more and better content, more and better access, convenience, and new capabilities to do things that they have never been able to do before. They want the ability to manage costs, to participate and control their information environments, and the want individual and organizational 
productivity. Users want technology and content ubiquity. They not only want technological sandboxes places for experimentation and fun, - but also privacy spaces that afford both protection and anonymity. They want support services - help when needed - at appropriate levels of expertise. They want guidance to community resources and assistance with health issues, jobs, and their careers. They want community. How can we migrate from the insanity of return on investment (ROI) and focus more on the human objectives, the qualitative benefits of what we do for our community? How can we help users attain their goals, achieve well-being, realize their benefits, move forward, make personal connections, participate fully, and have significant effect in their worlds through us? How do we draw an effective line between what we do and the success of students and citizens, and the productivity of faculty and researchers productivity How do we align between campus, community, and the economy? How do we contribute to the health, values, and reputations of our community? These, I believe, will be important questions to be answered as we move forward.

\section{Commandment \#4: "Thou shall cooperate in new and more rigorous ways."}

Cooperation is part of our DNA. But we need more radical strategies for collaboration among libraries, publishers, and the scholarly intermediary communities. We need deeper integration of operations in areas of mass production, where we have hopeless redundancy. We need early co-investment as we build new infrastructures and develop new initiatives. We need a commitment to a shared network of centers of excellence, from the conditions of knowledge scarcity to the oppression of information overabundance. Cooperation will be a constant for service success and survival. Our future health will be increasingly defined not by sharing resources on the margins, but by new and energetic relationships and combinations, and on innovative entrepreneurial partnerships.

We are in a period of polygamy, of rampant partnering and combinations. Are we ready to move into a period of parabiosis and synergy with selective and deep collaborations? And are we advancing to a period of particularism, with powerful disciplinary service technology and workflow specializations and inter-dependencies? We must move beyond the rhetoric of conflict and parallelism in our world that has defined the relationship among libraries, publishers, and information intermediaries.

Commandment \#5: "Thou shall work together to improve knowledge creation, evaluation, distribution, use, and preservation."

Researchers have the urge to share the results of their investigations through publications. This has been the way they communicate with peers and students around the world. It is part of the academic culture in which they have been raised. It is the way their ideas and their contributions are preserved for future generations. It is their source of prestige, recognition, and remuneration. Researchers are telling us they need support in several critical areas. They are seeking assistance in navigating, analyzing, and synthesizing a literature with which they simply cannot keep up, especially when they move into new and multidisciplinary fields.

They want guidance on working in an open research environment, with scholarly exchange that is continuous and meaningful. They require more robust expertise databases, subject ontologies, and research information systems. They expect more consultation and support with research data management. They want help with awareness and integration of disparate sources and the gray literature. They argue for more of an informationalist and partnership model for support of their work. Researchers remind us that they work in diverse disciplinary communities. They emphasize the importance of trust, credibility, organized skepticism, and meritocracy in the scholarly process. They recognize that there is a new economics governing research, what is considered important, and what is supported. They see the power of 
digital and networked information- big data- to produce wider vertical integration in research, new modes of scholarly discourse, expanded readership of research results on a global scale, and a democratization of the research process more reliant on the open and free exchange.

How can we together better support these shifting research conditions? I hope that the ideas embodied in these five commandments are provocative and useful and that we, librarians, publishers, and information intermediaries, can move forward together as one united community.

\begin{abstract}
About the Author
Jim Neal is University Librarian Emeritus at Columbia University. He served as the Vice President for Information Services and University Librarian at Columbia University during 2001-2014, providing leadership for university academic computing and a system of twenty-two libraries. Neal has served in many leadership capacities in the information community. For example he served as President of the American Library Association 2017-2018 and is currently a member of the OCLC Board of Trustees. He has served on the Board and as President of the Association of Research Libraries, on the Board and as Chair of the Research Libraries Group (RLG), on the Board and as Chair of the National Information Standards Organization (NISO), and on the Board of the Digital Preservation Network. He is on the Board and is the Treasurer of the Freedom to Read Foundation, and is on the Board and has served as Treasurer of the Metropolitan New York Library Council (METRO).

Neal has been honored many times for his significant contributions. He was selected the 1997 Academic Librarian of the Year by the Association of College and Research Libraries and was the 2007 recipient of ALA's Hugh Atkinson Memorial Award and the 2009 ALA Melvil Dewey Medal Award. In 2010, he received the honorary Doctor of Laws degree from the University of Alberta. In 2015, he received the ALA Joseph W. Lippincott Award for "distinguished service to the profession of librarianship", and the Freedom to Read Foundation Roll of Honor Award. In 2016, he was awarded the Scroll of Appreciation by the International Federation of Library Associations (IFLA). And he was the recipient of the 2020 Miles Conrad Award from the National Information Standards Organization and the National Federation of Advanced Information Services. E-mail: jneaql@columbia.edu.
\end{abstract}

\title{
References
}

[1] Established in 1968 by the National Federation of Advanced Information Services (NFAIS), this award recognizes those have made significant contributions to the global information community. Named in honor of G. Miles Conrad (19111964) who was a key individual responsible for the founding of NFAIS, awardees are invited to present a special lecture to an audience of their peers during the annual conference. Throughout the years, industry leaders, innovators and pioneers from across every sector of the information community have enthralled conference attendees with their insights, reflections, anecdotes, and wisdom during the Miles Conrad Memorial Lecture. For a list of awardees through 2018 go to: https://www.niso.org/node/25942, accessed July 29, 2020.

[2] R.W. Emerson, from a journal entry made on April 19, 1838 regarding a letter he sent to President Van Buren, see: https://quod.lib.umich.edu/e/emerson/4957107.0011.001/1:37.3?rgn=div2;view=fulltext, last accessed June 11, 2020. 